\title{
IKERLANAK
}

\section{CHOICE OF FLEXIBLE PRODUCTION TECHNOLOGIES UNDER STRATEGIC DELEGATION}

by

Juan Carlos Bárcena-Ruiz and Norma Olaizola

2004

Working Paper Series: IL. 13/04

Departamento de Fundamentos del Análisis Económico I

Ekonomi Analisiaren Oinarriak I Saila

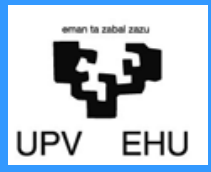

University of the Basque Country 


\title{
Choice of Flexible Production Technologies under Strategic Delegation
}

\author{
Juan Carlos Bárcena-Ruiz and Norma Olaizola ${ }^{* \dagger}$
}

September 2004

\begin{abstract}
This work analyzes a managerial delegation model in which firms can choose between a flexible production technology which allows them to produce two different products and a dedicated production technology which limits production to only one product. We analyze whether the incentives to adopt the flexible technology are smaller or greater in a managerial delegation model than under strict profit maximization. We obtain that the asymmetric equilibrium in which only one firm adopts the flexible technology can be sustained under strategic delegation but not under strict profit maximization when products are substitutes. We extend the analysis to consider welfare implications.
\end{abstract}

JEL Classification: O31, L13

Key words: Flexible production technologies, strategic delegation, social welfare, duopoly

\footnotetext{
*Departamento de Fundamentos del Análisis Económico I. Facultad de Ciencias Económicas y Empresariales. University of the Basque Country. Avenida Lehendakari Agirre 83, 48015, Bilbao, Spain. e-mails: jepbaruj@bs.ehu.es (J.C. Bárcena-Ruiz), etpolorn@bs.ehu.es (N. Olaizola). Phone: + 349460170 75. Fax: + 34946013891.

†The authors gratefully acknowledge financial support from Ministerio de Ciencia y Tecnología and FEDER (BEC2003-04430, BEC2003-08182) and UPV-EHU (Subvención a grupos).
} 


\section{Introduction}

Although it is generally accepted that modern corporations are characterized by a division between ownership and management, technology choice literature usually treats firms as economic agents which maximize strict profits (see for example Bester and Petrakis (1993), Röller and Tombak (1990)). Seeking to set our study in a more realistic framework, we analyze the incentives to adopt flexible technologies in a managerial strategic delegation model.

The literature on strategic delegation (see Vickers (1985), Fershtman and Judd (1987), Sklivas (1987)), analyzes the incentive contracts that owners of competing firms give their managers and how these incentive contracts affect the oligopoly outcome. These studies show that firms' owners are interested in driving their managers away from strict profit maximization for strategic reasons.

In this work, like Fershtman and Judd (1987), we assume that firms' managers will be given an incentive to maximize an objective function consisting of a linear combination of profits and sales revenue. We consider that firms have to choose between two production technologies: a flexible technology, which allows firms to produce two different products and a dedicated technology which limits production to a single product. We analyze how strategic delegation contracts affect firms' decisions between these two types of technology.

Let us first explain the difference between flexible and dedicated technologies. Elkins et al. (2003) define a dedicated machining system as that which can produce only a single product model. By contrast, a flexible machining system is an adaptable system that can change quickly and easily to produce a planned range of product classes and product models, with a product model being a specific variant within a product class. They analyze the automotive industry and argue that the initial investment needed to implement a dedicated technology which allows a single engine to be produced is greater than the in- 
vestment needed to adopt a flexible technology which allows the production of several different engine models. We set our model in this context. Moreover, the investment needed to implement any technology is assumed to be exogenous, so we do not consider licensing of production technologies. ${ }^{1}$

Röller and Tombak (1990) and Kim et al. (1992) propose a game in which firms' owners choose between a flexible technology and a dedicated one. They examine market conditions under which strict profit-maximizer firms would choose a flexible technology. They find that when the difference in fixed costs between the two technologies (denoted as $F$ ) is sufficiently low, both firms adopt the flexible technology. By contrast, when $F$ is sufficiently high, neither firm adopts the flexible technology. The asymmetric equilibrium in which only one firm adopts the flexible technology does not exist when products are substitutes. They find that consumer (producer) surplus is largest when both firms adopt the flexible (dedicated) technology. However, the results on total surplus depend on the value of parameter $F$. In general, the larger the value of $F$, the lower the benefit that the economy obtains from the adoption of flexible technologies. As a result, a welfare-maximizer agent would encourage both firms to adopt the flexible technology for low enough values of $F$ and the dedicated technology for high enough values of $F$. There are no values of $F$ for which one firm adopting the flexible technology and the other firm the dedicated one maximizes total surplus.

By contrast, our model takes into account the fact that owners' delegation of production decisions to managers has strategic effects which modify equilibrium outcomes. We consider an oligopolistic industry consisting of two firms that produce a differentiated product in which firms' owners have to choose the incentive contracts that are given to managers. We analyze how those incentive contracts affect the production technology choice in the context of Röller and

\footnotetext{
${ }^{1}$ Assuming an innovator who sets the price of an innovation, Saracho (2002) analyzes firms' technology choice in a context of strategic delegation by considering $n$ firms that produce a homogeneous good.
} 
Tombak (1990). Let us briefly explain how strategic delegation influences the production technology choice. As in Röller and Tombak (1990) and Kim et al. (1992), we find that when $F$ is sufficiently low (high), both firms adopt the flexible (dedicated) production technology. However, unlike under strict profit maximization, when firms' owners delegate production decisions the asymmetric equilibrium in which only one firm adopts the flexible technology does exist when products are substitutes. We also find that the incentives to adopt the flexible technology are smaller than under strict profit maximization. The intuition behind these results lies in the fact that the lower marginal cost of production considered by firms' managers under strategic delegation results in firms producing a larger quantity of each product than in the strict profit maximization case. This increases market competition and, therefore firms's profits decrease. Consequently, the incentive to specialize in one product is larger under strategic delegation than under strict profit maximization since the adoption of the dedicated technology decreases market competition. It must be noted that when a firm adopts the flexible technology, it produces two goods that are substitutes. However, a firm adopting the dedicated technology serves only one market.

We also extend the analysis on welfare implications considered by Röller and Tombak (1990) since the expression they use to measure consumer surplus is valid only when products are independent in demand. When analyzing the efficiency of the equilibrium outcomes we find that market competition leads to a lower adoption of flexible technologies under strategic delegation and a higher adoption under strict profit maximization than the adoption level needed to maximize total surplus. Moreover, the range of parameter values for which the equilibrium technology choice is non-efficient is larger under strategic delegation than under strict profit maximization.

In this work, we characterize manufacturing flexibility in terms of the possibility of producing different products. By contrast, Tseng (2003) focuses on the manufacturing flexibility that allows a firm to produce with shorter expected 
delivery times. The firm that makes the fastest delivery can sell the product at a given price, while firms who do not deliver first must sell their product at discount prices. Some other studies introduce uncertainty when analyzing technology adoption (see Anderson and Engers (1994), Hoppe (2000) and Götz (2000)). In a context of managerial delegation, Bárcena-Ruiz and Olaizola (2004) examine firms' incentives to choose between dedicated production technologies which have different characteristics.

The rest of the paper is organized as follows. In Section 2 we describe the general features of a differentiated duopoly model under strategic delegation. In Section 3 we characterize the equilibrium under strict profit maximization and strategic delegation and analyze how owners' delegation of production decisions to managers affects the equilibrium outcome. In Section 4 we study the welfare implications of our model. Lastly, Section 5 presents some conclusions.

\section{The model}

We consider a single industry consisting of two firms (1 and 2) that can produce two differentiated products ( $A$ and $B$ ). Two markets exist, one for product $A$ and one for product $B$. Each firm can choose between two different production technologies: a flexible manufacturing system (denoted by subscript $f$ ), which allows firms to produce both products, and a dedicated equipment (denoted by subscript $d$ ), which limits production to only one of the two products.

We consider marginal cost of production, denoted as $c$, as being equal for both technologies. ${ }^{2}$ The fixed costs associated with each technology are $F_{f}$ for the flexible technology and $F_{d}$ for the dedicated technology, with $F_{f}>F_{d}$. Without loss of generality we normalize $F_{d}$ to zero and denote $F_{f}=F$. Hence, $F$ represents the difference in fixed costs between the two technologies.

Following Vives (1985), our model considers a representative consumer that

\footnotetext{
${ }^{2}$ Röller and Tombak (1990) justify this assumption by empirical observation.
} 
maximizes a quadratic utility function of the form:

$$
U\left(q^{A}, q^{B}, I\right)=a\left(q^{A}+q^{B}\right)-\frac{1}{2}\left(q^{A}\right)^{2}-\frac{1}{2}\left(q^{B}\right)^{2}-b q^{A} q^{B}+I,
$$

where $I$ represents a numeraire good. The first order conditions for the utility maximization problem lead to the following inverse demand system:

$$
p^{k}=a-q^{k}-b q^{l}, a>c, k \neq l ; k, l=A, B,
$$

where $p^{k}$ and $q^{k}=q_{1}^{k}+q_{2}^{k}$ are the price and the total quantity of product $k$, respectively, and $q^{l}=q_{1}^{l}+q_{2}^{l}$ denotes the total quantity of product $l$. We assume $0 \leq b<1$ and products $A$ and $B$ are thus considered as substitutes with the own price effect dominating the cross price effect. ${ }^{3}$

If both firms choose the dedicated technology, we set without loss of generality that firm $i$ enters market $A$ and firm $j$ market $B$ (i.e. $q_{i}^{B}=q_{j}^{A}=0, i \neq j$; $i, j=1,2)$. If only one firm chooses the flexible technology, we set that the firm with the dedicated technology serves only market $A$.

Each firm's owner delegates production decisions to a risk neutral manager. As in Fershtman and Judd (1987), we consider linear incentive contracts that are a function of profits and sales revenue. The contract is such that firm $i$ 's manager $(i=1,2)$ receives a payoff $\beta_{i}+B_{i} O_{i}$, where $\beta_{i}$ and $B_{i}>0$ are constant and $O_{i}$ is a linear combination of profits and sales revenue. The terms $\beta_{i}$ and $B_{i}$ are chosen by firm $i$ 's owner so that the manager only gets his opportunity cost, which is normalized to zero. The contract must be legally enforceable, irreversible and observable. Formally, firm $i$ 's manager will be given an incentive to maximize:

$$
O_{i}=\alpha_{i} \Pi_{i}+\left(1-\alpha_{i}\right) S_{i}, i=1,2,
$$

where $\Pi_{i}=\left(p^{A}-c\right) q_{i}^{A}+\left(p^{B}-c\right) q_{i}^{B}-F_{i}$ and $S_{i}=p^{A} q_{i}^{A}+p^{B} q_{i}^{B}$ are firm $i$ 's profits and sales revenue, respectively, and $\alpha_{i}$ is the incentive parameter chosen

\footnotetext{
${ }^{3}$ The model can easily be extended to assume complementary products by considering $-1<b<0$.
} 
by firm $i$ 's owner. We make no restrictions on $\alpha_{i}$. Rewriting (1) we obtain:

$$
O_{i}=\left(p^{A}-c \alpha_{i}\right) q_{i}^{A}+\left(p^{B}-c \alpha_{i}\right) q_{i}^{B}-\alpha_{i} F_{i}, i=1,2 .
$$

As (2) shows, firm $i$ 's manager considers $\alpha_{i} c$ as the marginal cost of production for each good. As a result, if firm $i$ 's owner chooses $\alpha_{i}<1\left(\alpha_{i}>1\right)$, the marginal cost of production considered by his manager is lower (larger) than that considered by a profit-maximizer firm. In this way, firm $i$ 's owner makes his manager more (less) aggressive, i.e. his manager produces a higher (lower) output level than under strict profit maximization.

We model the study of production technology choice under strategic delegation as a game in three stages. In the first stage, owners simultaneously choose the production technology. In the second stage, owners simultaneously determine the incentive structure for their managers. Finally, in the third stage, managers simultaneously take production decisions, with each firm's manager knowing his incentive contract and that of the competing manager. We assume that managers are perfectly aware of the nature of demand and costs. The above timing of decisions is based on the fact that the production technology choice is a more long-term decision than the setting of managers' incentives.

Figure 1 summarizes the state of the game in the first stage. We solve the game by backward induction from the last stage to obtain a subgame-perfect Nash equilibrium.

\section{[INSERT FIGURE 1 AROUND HERE]}

In Figure 1, $\Pi(f f)$ denotes the profit of a firm that chooses the flexible technology when both firms choose this technology. $\Pi(d d)$ denotes the profit of a firm that chooses the dedicated technology when both firms choose this technology. When only one firm adopts the flexible technology, $\Pi(f d)$ denotes the profit of the firm that chooses the flexible technology and $\Pi(d f)$ denotes the profit of the firm that chooses the dedicated one. If a firm is indifferent between the two technologies we assume that it chooses the flexible one. 
We next characterize the equilibria.

\section{Characterization of the equilibria}

To show how strategic delegation affects firms' decisions, we consider first the simple profit maximization case.

\subsection{Benchmark case: Profit-maximizer firms}

In this case we have a two stage game. In the first stage, owners simultaneously choose the production technology. And in the second stage owners simultaneously choose outputs.

In stage two, firm $i$ 's owner chooses $q_{i}^{A}$ and $q_{i}^{B}$ to maximize $\Pi_{i}$ taking the competitor's quantities, $q_{j}^{A}$ and $q_{j}^{B}$, as fixed. ${ }^{4}$ We solve this second stage of the game for each case in Figure 1. This problem leads to the equilibrium quantities and profits given in Table $1 .{ }^{5}$

Taking into account the outcomes described in Table 1, in the first stage of the game, firms' owners simultaneously choose the production technology. Solving this first stage we obtain the following result. ${ }^{6}$ Let:

$$
F_{1}=\frac{(a-c)^{2}(1-b)\left(16+12 b+5 b^{2}\right)}{36(1+b)(2+b)^{2}}
$$

where $F_{1}$ is the investment needed to adopt the flexible technology such that $\Pi(f d)=\Pi(d d)$.

Lemma 1 When firms' owners do not delegate production decisions to managers, in equilibrium:

i) Both firms choose the flexible technology if $F \leq F_{1}$.

ii) Both firms choose the dedicated technology if $F>F_{1}$.

\footnotetext{
${ }^{4}$ It must be noted that, without loss of generality, our model assumes $q_{i}^{B}=q_{j}^{A}=0$ when both firms adopt the dedicated technology and $q_{j}^{B}=0$ when firm $i$ adopts the flexible technology and firm $j$ adopts the dedicated one.

${ }^{5}$ All tables are relegated to the appendix.

${ }^{6}$ The same result is given by Röller and Tombak (1990) and Kim et al. (1992).
} 
As Lemma 1 shows, if parameter $F$ is sufficiently low $\left(F \leq F_{1}\right)$ both firms adopt the flexible technology. The reason is that due to the low investment that the adoption of the flexible technology requires in this case, neither firm finds it profitable to lock itself out of half of the market. By contrast, if parameter $F$ is sufficiently high $\left(F>F_{1}\right)$ both firms adopt the dedicated technology. In this case, due to the high investment that the adoption of the flexible technology requires, neither firm finds it profitable to serve both markets. In this way, each firm will be a monopolist in one market. ${ }^{7}$ Note that one firm adopting the flexible technology and the other firm adopting the dedicated technology cannot be an equilibrium in this case. ${ }^{8}$

It can be shown that $F_{1}$ decreases with $b$ and increases with $a$. As a result, the lower parameter $b$ and the higher parameter $a$, the biggger the incentive to adopt the flexible technology. As Röller and Tombak (1990) note, one can interpret a low $b$ as the situation in which the two products are perceived by consumers as being highly differentiated. When this is the case any firm choosing the dedicated technology locks itself out of almost half of the market, hence the natural tendency to invest in a flexible technology. A high $a$ represents large markets, encouraging more active participation of firms in both markets. By contrast, the higher parameter $b$ and the lower parameter $a$, the larger the incentive to adopt the dedicated technology. Thus, when the two products are perceived by consumers as being close substitutes, firms tend to specialize in one product. A low $a$ represents small markets, discouraging the active participation of firms in both markets.

\footnotetext{
${ }^{7}$ Let $F_{2}=(a-c)^{2}(1-b) / 9(1+b)$ be the investment needed to adopt the flexible technology such that $\Pi(d f)=\Pi(f f)$. When $F_{1}<F<F_{2}$, two equilibria exist: $(d d)$ and $(f f)$. However, it can easily be seen that $\Pi(d d)>\Pi(f f)$ for all $F$. Consequently, equilibrium $(d d)$ Pareto dominates equilibrium $(f f)$.

${ }^{8}$ Considering complementary products $(-1<b<0)$ we have that $F_{1}>F_{2}$. Thus, for $F_{2}<F \leq F_{1}$ it is possible to obtain $(f d)$ and $(d f)$ equilibria with complementary products (see Kim et al. (1992)).
} 


\subsection{Strategic delegation}

When firms' owners hire managers to take production decisions we have a three stage game. In the first stage, owners simultaneously choose the production technology. In the second stage, owners simultaneously determine the incentive structure for their managers. Finally, in the third stage, managers simultaneously choose outputs.

In stage three, firm $i$ 's manager chooses $q_{i}^{A}$ and $q_{i}^{B}$ to maximize (2) taking the competitor's outputs, $q_{j}^{A}$ and $q_{j}^{B}$, as fixed. The objective function of firm $i$ 's manager can be written as:

$$
O_{i}=\left(a-q^{A}-b q^{B}-c \alpha_{i}\right) q_{i}^{A}+\left(a-q^{B}-b q^{A}-c \alpha_{i}\right) q_{i}^{B}-\alpha_{i} F_{i}
$$

where $q^{A}=q_{i}^{A}+q_{j}^{A}$ and $q^{B}=q_{i}^{B}+q_{j}^{B}, i \neq j ; i, j=1,2$. Solving this third stage of the game for all cases we obtain the following results:

If both firms adopt the flexible technology:

$$
q_{i}^{A}=q_{i}^{B}=\frac{a+c\left(\alpha_{j}-2 \alpha_{i}\right)}{3(1+b)}, q_{j}^{A}=q_{j}^{B}=\frac{a+c\left(\alpha_{i}-2 \alpha_{j}\right)}{3(1+b)} .
$$

If both firms adopt the dedicated technology:

$$
q_{i}^{A}=\frac{(2-b) a+c\left(b \alpha_{j}-2 \alpha_{i}\right)}{(4-b)^{2}}, q_{i}^{B}=0, q_{j}^{A}=0, q_{j}^{B}=\frac{(2-b) a+c\left(b \alpha_{i}-2 \alpha_{j}\right)}{(4-b)^{2}} .
$$

If firm $i$ adopts the flexible technology and firm $j$ the dedicated one:

$$
q_{i}^{A}=\frac{(2-b) a+c\left(2(1+b) \alpha_{j}-(4+b) \alpha_{i}\right)}{6(1+b)}, q_{i}^{B}=\frac{a-c \alpha_{i}}{2(1+b)}, q_{j}^{A}=\frac{a+c\left(\alpha_{i}-2 \alpha_{j}\right)}{3}, q_{j}^{B}=0 .
$$

Taking into account the results obtained in the third stage of the game, in the second stage, firm $i$ 's owner chooses the incentive parameter of his manager, $\alpha_{i}$, that maximizes his firm's profit taking the competitor's incentive parameter, $\alpha_{j}$, as fixed. Solving this problem we obtain the equilibrium quantities, profits and incentive parameters given by Table 2. Note that $\alpha_{i}<1$ for all equilibria. Consequently, firm $i$ 's manager considers a lower marginal cost of production than a profit-maximizer firm. Thus, firm $i$ 's owner makes his manager more 
aggressive (i.e. his manager produces a larger quantity of each product) than a profit-maximizer firm.

We can also check that $\alpha(d d)>\alpha(f d)>\alpha(f f)>\alpha(d f)$. Then, when one firm adopts the dedicated technology, its equilibrium incentive parameter is largest if the other firm also chooses the dedicated technology and smallest if the other firm chooses the flexible technology. We obtain intermediate equilibrium incentive parameter values for a firm that chooses the flexible technology, and they are smaller when the other firm chooses also the flexible technology. Let us interpret this result. When both firms adopt the dedicated technology, each firm acts as a monopolist in its own market and thus each firm's owner encourages his manager to behave non-aggressively. Hence the largest value of the incentive parameter for $(d d)$ equilibrium. On the other hand, when a firm chooses the flexible technology its manager must decide the output level of the two products. Since we are considering substitute products, this manager must internalize the fact that the two goods he produces compete in the same market. As a result, when the other firm adopts the flexible technology, a firm's owner will provide less aggressive incentives to his manager if adopting the flexible technology rather than the dedicated one, i.e. $\alpha(f f)>\alpha(d f)$. Lastly, a firm that adopts the flexible technology will be more aggressive if the other firm also adopts the flexible technology due to the greater market competition that this situation implies, hence $\alpha(f d)>\alpha(f f) .9$

Taking into account the outcomes described in Table 2, in the first stage of the game firms' owners simultaneously choose the production technology. Solving this first stage we obtain the following result. Let:

\footnotetext{
${ }^{9}$ Bárcena-Ruiz and Espinosa (1997) analyze a related question. By considering multiproduct firms, they study whether firms' owners delegate all production decisions to one manager (i.e. they centralize production decisions) or each good's production decision is delegated to a different manager (i.e. they decentralize production decisions). They show that when goods are substitutes, firms behave more aggressively in the product markets if production decisions are decentralized.
} 


$$
\begin{aligned}
& F_{1 s}=\frac{(a-c)^{2}(1-b)\left(b^{6}-24 b^{5}+159 b^{4}-172 b^{3}-1092 b^{2}-336 b+544\right)}{4(11-b)^{2}(1+b)\left(4+2 b-b^{2}\right)^{2}}, \\
& F_{2 s}=\frac{(a-c)^{2}(1-b)\left(25 b^{2}-208 b+343\right)}{50(11-b)^{2}(1+b)}
\end{aligned}
$$

where $F_{1 s}$ and $F_{2 s}\left(F_{1 s}>F_{2 s}\right)$ are the investments needed to adopt the flexible technology such that $\Pi(f d)_{s}=\Pi(d d)_{s}$ and $\Pi(d f)_{s}=\Pi(f f)_{s}$, respectively.

Proposition 1 When firms' owners delegate production decisions to managers, in equilibrium:

i) Both firms choose the flexible technology if $F \leq \min \left\{F_{1 s}, F_{2 s}\right\}$.

ii) Only one firm chooses the flexible technology if $F_{2 s}<F \leq F_{1 s}$.

iii) Both firms choose the dedicated technology if $F>F_{1 s} \cdot{ }^{10}$

Proposition 1 shows that the equilibrium outcome induced by market competition depends on both the degree of product substitutability (parameter $b$ ) and the difference in fixed costs between the two technologies (parameter $F$ ). Figure 2 summarizes the results described in this proposition.

\section{[INSERT FIGURE 2 AROUND HERE]}

It can be shown that $F_{1 s}$ is positive and decreases with $b$ if and only if $b<0.5584$, while $F_{2 s}$ decreases with $b$ for all $b \geq 0$. As a result, when the degree of product substitutability is high enough $(b>0.5584)$, no matter what value parameter $F$ takes, neither firm finds the adoption of the flexible technology profitable. Thus, when the two products are perceived by consumers as being close substitutes firms tend to specialize in one product regardeless of the difference in fixed cost between the two technologies. ${ }^{11}$ However, when products are perceived by consumers as being sufficiently differentiated $(b<0.5584)$, if

\footnotetext{
${ }^{10}$ When $F_{1 s}<F<F_{2 s}$ two equilibria exist: $(d d)$ and $(f f)$. However, it can easily be seen that $\Pi(d d)>\Pi(f f)$ for all $F$. Consequently, equilibrium $(d d)$ Pareto dominates equilibrium $(f f)$.

${ }^{11}$ This result is not obtained under strict profit maximization since $F_{1}>0$ for all $b$.
} 
$F \leq \min \left\{F_{1 s}, F_{2 s}\right\}$ both firms adopt the flexible technology while if $F>F_{1 s}$ both firms adopt the dedicated one.

On the other hand, straightforward computations show that $F_{1 s}>F_{2 s}$ if and only if $b<0.1649$. As a result, for a low enough degree of product substitutability $(b<0.1649)$ there are intermediate values of $F\left(F_{2 s}<F \leq F_{1 s}\right)$ for which $(f d)$ and $(d f)$ equilibria can be supported (i.e. only one firm adopts the flexible technology). Thus, unlike under strict profit maximization, when firms' owners delegate quantity decisions asymmetric equilibria do exist when products are substitutes. We find various reasons for the existence of these asymmetric equilibria. A low degree of product substitutability leads to low competition between the two products, hence the large incentive of firms to serve both markets. However, due to the lower marginal cost of production considered by firms' managers under strategic delegation than under strict profit maximization, firms produce a larger quantity of each product. This leads to a higher market competition and therefore, to smaller profits for firms. Moreover, we have seen that $\alpha(f d)>\alpha(d f)$ which means that a firm that adopts the dedicated technology behaves more aggressively than a firm that adopts the flexible one. As a result, the latter firm obtains a greater market share than the former in the market in which the two firms compete. On the other hand, the firm that adopts the flexible technology is a monopolist in one of the markets. In this case, parameter $\mathrm{b}$ is low enough $(\mathrm{b}<0.1649)$ and thus the firm that adopts the dedicated technology has a strategic advantage in the market in which the two firms compete while the firm that adopts the flexible technology has a strategic advantage in the market in which it is a monopolist. Therefore, for intermediate values of $F\left(F_{2 s}<F \leq F_{1 s}\right)$ only one firm adopts the flexible technology.

We can also check that both $F_{1 s}$ and $F_{2 s}$ increase with $a$. Hence, when markets are large, firms tend to invest in the flexible technology while if markets are small, firms tend to specialize in one product.

Next we compare the results obtained for both the strict profit maximization 
and the strategic delegation cases.

\subsection{Comparison of results}

From Lemma 1 and Proposition 1 we obtain the following result.

Proposition 2 When firms' owners do not delegate production decisions to managers, the incentives to adopt the flexible technology are at least as large as under strategic delegation. ${ }^{12}$

Figure 3 summarizes the results obtained under strict profit maximization and strategic delegation.

\section{[INSERT FIGURE 3 AROUND HERE]}

Straightforward computations show that $F_{1}>F_{i s}, i=1,2$. On the other hand, we have seen that $F_{1 s}>F_{2 s}$ if and only if $b<0.1649$. Therefore, if $0<b<0.1649$ we have $F_{1}>F_{1 s}>F_{2 s}$, while if $b \geq 0.1649$ we have $F_{1}>F_{2 s} \geq F_{1 s}$. These results will be of use in the interpretation of Proposition 2. If $F>F_{1}$, the two firms adopt the dedicated technology under both strict profit maximization and strategic delegation. If $F \leq \min \left\{F_{1 s}, F_{2 s}\right\}$, the two firms adopt the flexible technology in both cases. If $F_{1 s}<F \leq F_{1}$, both firms adopt the dedicated technology under strategic delegation while both firms choose the flexible technology under strict profit maximization. Lastly, if $F_{2 s}<F \leq F_{1 s}$, only one firm adopts the flexible technology under strategic delegation while both firms adopt it under strict profit maximization. We can thus conclude that when firms' owners do not delegate production decisions, the incentives to adopt the flexible technology are at least as great as under strategic delegation. The intuition behind the above result is that due to the lower marginal cost of production considered by firms' managers under strategic delegation than under strict profit maximization, firms produce a larger quantity

\footnotetext{
${ }^{12}$ The same result is obtained when considering complementary products.
} 
of each product. This increases market competition and therefore, firms' profits decrease. Consequently, the difference in fixed cost between the two technologies that a firm can afford when adopting the flexible technology is smaller under strategic delegation. As a result, a firm's incentive to specialize in one product (i.e. to be a monopolist in its own market) is at least as great under strategic delegation as under strict profit maximization.

\section{Welfare implications}

Given that we consider a representative consumer that maximizes a quadratic utility function, consumer surplus is:

$$
C S=\frac{1}{2}\left(q^{A}\right)^{2}+\frac{1}{2}\left(q^{B}\right)^{2}+b q^{A} q^{B},
$$

where $q^{A}$ and $q^{B}$ are the total equilibrium quantities of products $A$ and $B$, respectively. Producer surplus, denoted as $P S$, is given by the sum of firms' profits. Total surplus (welfare), denoted as $W$, is the sum of $C S$ and $P S$.

We next analyze $C S, P S$ and $W$ under strict profit maximization and strategic delegation. We first study the strict profit maximization case.

\subsection{Benchmark case: Profit-maximizer firms}

Consumer, producer and total surpluses under strict profit maximization are given in Table 3. Straightforward computations lead to the following result. ${ }^{13}$ Let:

$$
F_{1}^{w}=\frac{5(a-c)^{2}(1-b)}{72(1+b)}, F_{2}^{w}=\frac{(a-c)^{2}(1-b)(5+b)}{18(1+b)(2+b)^{2}}, F_{3}^{w}=\frac{(a-c)^{2}(1-b)\left(20-12 b-5 b^{2}\right)}{72(1+b)(2+b)^{2}},
$$

where $F_{1}^{w}, F_{2}^{w}$ and $F_{3}^{w}\left(F_{1}^{w}>F_{2}^{w}>F_{3}^{w}\right)$ are the investments needed to adopt the flexible technology such that $W(f f)=W(f d), W(f f)=W(d d)$ and $W(f d)=W(d d)$, respectively.

\footnotetext{
${ }^{13}$ This section extends the analysis on welfare implications considered by Röller and Tombak (1990) since the expression they use to measure consumer surplus is valid only when the two goods are independent in demand $(b=0)$.
} 
Lemma 2 When firms' owners do not delegate production decisions to managers, we obtain that $C S(f f)>C S(f d)>C S(d d)$ and $P S(d d)>P S(f d)>$ $P S(f f)$.

As Lemma 2 shows, consumer surplus is highest when both firms adopt the flexible technology and lowest when both firms adopt the dedicated one. Thus, consumers benefit from the adoption of the flexible technology since market competition is stronger when a firm adopts this technology (i.e. serves the two markets) rather than choosing the dedicated one (i.e. serving only one market). Moreover, it can easily be shown that $C S(f f), C S(f d)$ and $C S(d d)$ are all decreasing in $b$. Thus, consumers benefit from highly differentiated markets. On the other hand, due to the stronger market competition that the adoption of the flexible technology implies, the producer surplus is highest when both firms adopt the dedicated technology and lowest when both firms adopt the flexible one. Thus, producers benefit from the adoption of dedicated technologies. However, from Lemma 1 we know that both firms decide to adopt the dedicated technology if and only if $F>F_{1}$ holds. As Röller and Tombak (1990) note, this last means that market forces driving the introduction of flexible technologies yield a transfer of surplus from producers to consumers.

We next analyze total surplus. It is easy to see that if $F \leq F_{3}^{w}, W(f f)>$ $W(f d) \geq W(d d)$; if $F_{3}^{w}<F \leq F_{2}^{w}, W(f f) \geq W(d d)>W(f d)$; if $F_{2}^{w}<F \leq$ $F_{1}^{w}, W(d d)>W(f f) \geq W(f d)$ and if $F>F_{1}^{w}, W(d d)>W(f d)>W(f f)$. This leads to the following result.

Proposition 3 When firms' owners do not delegate production decisions to managers, total surplus is highest if both firms adopt the flexible technology when $F \leq F_{2}^{w}$ and if both firms adopt the dedicated technology when $F>F_{2}^{w} \cdot{ }^{14}$

\footnotetext{
${ }^{14}$ If we consider complementary products then $F_{3}^{w}>F_{2}^{w}>F_{1}^{w}$. In this case, total surplus is highest in $(f f)$ when $F \leq F_{1}^{w}$, in $(d f)$ when $F_{1}^{w}<F \leq F_{3}^{w}$ and in $(d d)$ when $F>F_{3}^{w}$.
} 
We know from Lemma 2 that consumers benefit from the adoption of flexible technologies while producers benefit from the adoption of dedicated technologies. So, Proposition 3 states that as long as the difference in fixed costs between the two technologies is sufficiently low, the benefit that consumers obtain from firms' adoption of flexible technologies is high enough to offset the loss that firms sustain. However, for large values of $F$, the adoption of flexible technologies induces a producer surplus decrease which overtakes the benefit that consumers obtain. Note that since total surplus includes the sum of profits of the two firms, total surplus does not consider the strategic effects that arise from the choice of technology made by firms' owners. These results together with Lemma 1 lead to the following.

Proposition 4 When firms' owners do not delegate production decisions to managers, the equilibrium technology chosen by firms' owners is non-efficient if and only if $F_{2}^{w}<F<F_{1}$.

We know from Lemma 1 that for $F>F_{1}\left(F \leq F_{1}\right)$ both firms adopt the dedicated (flexible) technology. On the other hand, Proposition 3 states that maximum total surplus is reached if both firms adopt the dedicated (flexible) technology when $F>F_{2}^{w}\left(F \leq F_{2}^{w}\right)$. Moreover, it can be shown that $F_{1}>F_{2}^{w}$. Consequently, we can conclude the following. When $F>F_{1}\left(F \leq F_{2}^{w}\right)$, market competition induces both firms to adopt the dedicated (flexible) technology and total surplus is maximum. When $F_{2}^{w}<F \leq F_{1}$, both firms choose the flexible technology although the situation in which both firms adopt the dedicated one yields the maximum total surplus. Therefore, in this last case market competition leads to a non-efficient outcome. ${ }^{15}$ Let us interpret this result. As we have seen, when $F_{2}^{w}<F \leq F_{1}$, market forces lead to equilibrium $(f f)$. On the other hand, we know that the adoption of flexible technologies yields a transfer

\footnotetext{
${ }^{15}$ It can be shown that $\partial\left(F_{1}-F_{2}^{w}\right) / \partial b<0$ and consequently the closer substitutes the products are, the smaller the range of values of parameter $F$ is for which the equilibrium induced by market competition is non-efficient.
} 
of surplus from producers to consumers. However, when $F_{2}^{w}<F \leq F_{1}$, the larger production that the adoption of the flexible technology implies is not high enough for the consumer surplus increase to offset both the producer surplus decrease and the difference in fixed cost between the two technologies. It must be noted that in this case a welfare-maximizer agent prefers less market competition than in the equilibrium outcome.

We now turn to the strategic delegation case.

\subsection{Strategic delegation}

Consumer, producer and total surpluses under strategic delegation are given in Table 4. Straightforward computations lead to the following result. Let:

$$
\begin{aligned}
& F_{1 s}^{w}=\frac{3(a-c)^{2}(1-b)\left(719-264 b+25 b^{2}\right)}{200(11-b)^{2}(1+b)}, F_{2 s}^{w}=\frac{2(a-c)^{2}(1-b)(3+2 b)\left(7+b-3 b^{2}\right)}{25(1+b)\left(4+2 b-b^{2}\right)^{2}}, \\
& F_{3 s}^{w}=\frac{(1-b)(a-c)^{2}\left(1872+1168 b-732 b^{2}-540 b^{3}-41 b^{4}+36 b^{5}-3 b^{6}\right)}{8(11-b)^{2}(1+b)\left(4+2 b-b^{2}\right)^{2}}
\end{aligned}
$$

where $F_{1 s}^{w}, F_{2 s}^{w}$ and $F_{3 s}^{w}\left(F_{3 s}^{w}>F_{2 s}^{w}>F_{1 s}^{w}\right)$ are the investments needed to adopt the flexible technology such that $W(f f)_{s}=W(f d)_{s}, W(f f)_{s}=W(d d)_{s}$ and $W(f d)_{s}=W(d d)_{s}$, respectively.

Lemma 3 When firms' owners delegate production decisions to managers, we obtain that $C S(f f)_{s}>C S(f d)_{s}>C S(d d)_{s}$ and $P S(d d)_{s}>P S(f d)_{s}>$ $P S(f f)_{s}$.

Lemma 3 shows that consumer surplus is highest when both firms adopt the flexible technology and lowest when both firms adopt the dedicated one while producer surplus is highest when both firms adopt the dedicated technology and lowest when both firms adopt the flexible one. Thus, like under strict profit maximization, consumers benefit from the adoption of flexible technologies while producers benefit from the adoption of dedicated technologies. However, Proposition 1 states that both firms decide to adopt the dedicated technology if and only if $F>F_{1 s}$ holds. As a result, as under strict profit maximization, 
market forces driving the introduction of flexible technologies yield a transfer of surplus from producers to consumers.

We next analyze total surplus. It is easy to see that if $F \leq F_{1 s}^{w}, W(f f) \geq$ $W(f d)>W(d d)$; if $F_{1 s}^{w}<F \leq F_{2 s}^{w}, W(f d)>W(f f) \geq W(d d)$; if $F_{2 s}^{w}<F \leq$ $F_{3 s}^{w}, W(f d) \geq W(d d)>W(f f)$ and if $F>F_{3 s}^{w}, W(d d)>W(f d)>W(f f)$. This leads to the following result.

Proposition 5 When firms' owners delegate production decisions to managers, total surplus is highest if both firms adopt the flexible technology when $F \leq F_{1 s}^{w}$, if only one firm adopts the flexible technology when $F_{1 s}^{w}<F \leq F_{3 s}^{w}$ and if both firms adopt the dedicated technology when $F>F_{3 s}^{w} \cdot{ }^{16}$

Lemma 3 states that consumers benefit from the adoption of flexible technologies while producers benefit from the adoption of dedicated technologies. When analyzing total surplus, we find that as long as $F$ is sufficiently low, the benefit that consumers obtain from firms' adoption of flexible technologies is high enough to offset the loss that firms sustain. However, for sufficiently large values of $F$, the adoption of flexible technologies induces too high a producer surplus decrease which overtakes the benefit that consumers obtain. As a result, Proposition 5 states that the efficient outcome is $(f f)$ when $F$ is sufficiently small $\left(F \leq F_{1 s}^{w}\right)$ and $(d d)$ when $F$ is sufficiently large $\left(F>F_{3 s}^{w}\right)$. For intermediate values of $F\left(F_{1 s}^{w}<F \leq F_{3 s}^{w}\right)$, the efficient outcome is reached when only one firm adopts the flexible technology, i.e. $(f d)$. It must be noted that under strict profit maximization there is no range of values of $F$ for which $(f d)$ yields the maximum total surplus. This can be explained by the fact that under strategic delegation firms behave more aggressively than under strict profit maximization. As a result, for a given technology state, consumer surplus is higher and producer surplus is lower under strategic delegation than under strict profit maximization. This means that there exist intermediate values of $F$ for which the

\footnotetext{
${ }^{16}$ The same result holds when considering complementary products.
} 
consumer surplus increase that both firms' adoption of the flexible technology induces is not large enough to offset the producer surplus decrease. However, if one firm adopts the flexible technology, the output increase is large enough for the consumer surplus increase to offset the loss that firms sustain. These results together with Proposition 1, which characterizes the equilibria under strategic delegation, lead to Proposition 6. Figure 4 summarizes the results in Propositions 1 and 5.

\section{[INSERT FIGURE 4 AROUND HERE]}

Proposition 6 When firms' owners delegate production decisions to managers, the equilibrium technology chosen by firms' owners is non-efficient if and only if $\min \left\{F_{1 s}, F_{2 s}\right\}<F<F_{3 s}^{w}$.

Taking into account the results in Propositions 1 and 5 (see Figure 4) we obtain the following. When $F \leq \min \left\{F_{1 s}, F_{2 s}\right\}$, both firms adopt the flexible technology and total surplus is maximum. When $F_{2 s}<F \leq F_{1 s}$, only one firm adopts the flexible technology while the adoption of the flexible technology by the two firms maximizes total surplus. When $F>F_{1 s}$, neither firm adopts the flexible technology. However, $(f f)$ yields the maximum total surplus when $F_{1 s}<F \leq F_{1 s}^{w},(f d)$ yields the maximum total surplus when $F_{1 s}^{w}<F \leq F_{3 s}^{w}$ and lastly, $(d d)$ leads to the maximum total surplus when $F>F_{3 s}^{w}$. Therefore, when $\min \left\{F_{1 s}, F_{2 s}\right\}<F \leq F_{3 s}^{w}$ market competition leads to a non-efficient outcome while all other cases lead to an efficient outcome. ${ }^{17}$ Let us interpret the results shown in this proposition. As we have seen, the greater market competition induced by strategic delegation yields a larger incentive to adopt the dedicated technology than in the strict profit maximization case since the adoption of flexible technologies leads to even greater market competition. Moreover, the

\footnotetext{
${ }^{17}$ It can be shown that both $\partial\left(F_{3 s}^{w}-F_{2 s}\right) / \partial b$ and $\partial\left(F_{3 s}^{w}-F_{1 s}\right) / \partial b$ are negative and therefore, the closer substitutes the products are, the smaller the range of values of parameter $F$ is for which the equilibrium induced by market competition is non-efficient.
} 
higher production that the adoption of the flexible technology implies under strategic delegation is large enough for the consumer surplus increase to offset both the producer surplus decrease and the difference in fixed cost between the two technologies. It must be noted that a welfare-maximizer agent prefers a greater adoption of the flexible technology than that chosen by firms' owners. Then, in contrast with the result obtained for the strict profit maximization case, market competition induces a lower adoption of flexible technologies under strategic delegation than the level that maximizes social welfare.

Next we compare the results under strict profit maximization and strategic delegation.

\subsection{Comparison of results}

We first analyze whether a welfare-maximizer agent would prefer more adoption of flexible technologies under strategic delegation or under strict profit maximization. Comparing Propositions 3 and 5 we obtain the following result.

Proposition 7 From a total surplus maximization point of view, the flexible technology should be at least as widely adopted under strategic delegation as under strict profit maximization.

Proposition 3 states that under strict profit maximization, the maximum total surplus is induced by $(f f)$ when $F \leq F_{2}^{w}$ and by $(d d)$ when $F>F_{2}^{w}$. On the other hand, Proposition 5 states that under strategic delegation, the maximum total surplus is induced by $(f f)$ when $F \leq F_{1 s}^{w}$, by $(f d)$ when $F_{1 s}^{w}<F \leq F_{3 s}^{w}$ and by $(d d)$ when $F>F_{3 s}^{w}$. It can easily be shown that $F_{3 s}^{w}>F_{1 s}^{w}>F_{2}^{w}$, which leads to Proposition 7. The intuition behind this result is the following. Under strategic delegation firms behave more aggressively than under strict profit maximization. Market competition is thus greater under strategic delegation. Consequently, consumer surplus increases (and producer surplus decreases) with the introduction of flexible technologies relatively more under strategic delega- 
tion than under strict profit maximization. As a result, the difference in fixed cost between the two technologies that a welfare-maximizer agent accepts for adopting the flexible technology is larger under strategic delegation than under strict profit maximization.

We next compare the range of parameter values for which the equilibrium outcomes induced by strict profit maximization and strategic delegation are nonefficient. From Propositions 4 and 6 we see that under strategic delegation (strict profit maximization) a welfare-maximizer agent would induce a higher (lower) adoption of flexible technologies than that chosen by firms' owners. This result can be explained by the fact that under strategic delegation firms behave more aggressively and market competition is thus greater than under strict profit maximization. As a result, consumer surplus is higher and producer surplus is lower when firms' owners delegate production decisions. The adoption of flexible technologies leads to even greater market competition, hence the firms' tendency for a lower (from an efficiency point of view) adoption of flexible technologies under strategic delegation than under strict profit maximization. Moreover, when analyzing the parameter values for which equilibrium outcomes are efficient we find the following.

Proposition 8 The range of values of parameters $b$ and $F$ for which the equilibrium technology chosen by firms is non-efficient is larger under strategic delegation than under strict profit maximization.

Let us analyze the result in Proposition 8 more in detail. Proposition 4 states that when firms' owners do not delegate production decisions, the equilibrium technology choice is non-efficient if and only if $F_{2}^{w}<F<F_{1}$. On the other hand, from Proposition 6 we know that when firms' owners delegate production decisions, the equilibrium technology choice is non-efficient if and only if $\min \left\{F_{1 s}, F_{2 s}\right\}<F<F_{3 s}^{w}$. It can also be verified that $F_{3 s}^{w}>F_{1}>$ $F_{2}^{w}>\min \left\{F_{1 s}, F_{2 s}\right\}$. As a result, the range of values of parameters $b$ and $F$ for 
which the equilibrium technology choice is non-efficient is larger under strategic delegation than under strict profit maximization. The intuition behind this result is the following. Under strategic delegation firms behave more aggressively than under strict profit maximization which, in turn, leads to greater market competition. Consequently, consumer (producer) surplus increases (decreases) with the introduction of flexible technologies relatively more under strategic delegation than under strict profit maximization. The larger consumer surplus increase under strategic delegation leads to a larger incentive to adopt flexible technologies from a welfare maximization point of view. By contrast, the larger producer surplus decrease under strategic delegation leads to a lower incentive to adopt flexible technologies through market competition. Hence the grater range of parameter values for which under strategic delegation the equilibrium outcome and the efficient outcome do not coincide.

\section{Conclusions}

In this work we analyze how strategic incentives can affect firms' profits from the adoption of flexible technologies. We study a managerial delegation model consisting of two firms that can produce two differentiated products. Firms can choose between flexible and dedicated production technologies. We find that the incentives to adopt flexible technologies are smaller when firms' owners delegate production decisions to managers than in the strict profit maximization case. The intuition behind this result is that due to the lower marginal cost of production considered by firms' managers under strategic delegation when they compete by setting quantities, firms produce a larger quantity of each product than under strict profit maximization. This increases market competition and therefore firms's profits decrease. Consequently, the incentive to specialize in one product is larger under strategic delegation than under strict profit maximization since when a firm adopts the dedicated technology, it produces only one good and market competition thus decreases. It can be shown that the in- 
centive to specialize in one product is also larger under strategic delegation than under strict profit maximization when considering complementary products.

We also study the welfare implications of our model. We find that the introduction of flexible production technologies increases consumer surplus and decreases producer surplus under both strict profit maximization and strategic delegation. However, the results on total surplus depend on the difference in fixed costs between the two technologies (denoted as $F$ ). In general, the larger the value of parameter $F$ is, the lower the benefit is that the economy obtains from the adoption of flexible technologies.

When analyzing the efficiency of the equilibrium outcome induced by market competition we find that market competition induces a lower adoption of flexible technologies under strategic delegation and a higher adoption under strict profit maximization than the level that maximizes social welfare. However, the range of parameter values for which the equilibrium technology choice is non-efficient is larger under strategic delegation than under strict profit maximization. 


\section{Appendix}

\begin{tabular}{|l|l|l|l|}
\hline & $q_{i}^{A}$ & $q_{i}^{B}$ & $\Pi_{i}$ \\
\hline$f f$ & $\frac{a-c}{3(1+b)}$ & $\frac{a-c}{3(1+b)}$ & $\frac{2(a-c)^{2}}{9(1+b)}-F$ \\
\hline$f d$ & $\frac{(a-c)(2-b)}{6(1+b)}$ & $\frac{a-c}{2(1+b)}$ & $\frac{(a-c)^{2}(13-5 b)}{36(1+b)}-F$ \\
\hline$d f$ & $\frac{a-c}{3}$ & 0 & $\frac{(a-c)^{2}}{9}$ \\
\hline$d d$ & $\frac{a-c}{2+b}$ & 0 & $\frac{(a-c)^{2}}{(2+b)^{2}}$ \\
\hline
\end{tabular}

Table 1

Equilibrium under strict profit maximization

\begin{tabular}{|l|l|l|l|l|}
\hline & $\alpha_{i}$ & $q_{i}^{A}$ & $q_{i}^{B}$ & $\Pi_{i}$ \\
\hline$f f$ & $\frac{6 c-a}{5 c}$ & $\frac{2(a-c)}{5(1+b)}$ & $\frac{2(a-c)}{5(1+b)}$ & $\frac{4(a-c)^{2}}{25(1+b)}-F$ \\
\hline$f d$ & $\frac{12 c-a(1+b)}{c(11-b)}$ & $\frac{\left(7-4 b+b^{2}\right)(a-c)}{2(11-b)(1+b)}$ & $\frac{6(a-c)}{(11-b)(b+1)}$ & $\frac{(5-b)\left(31-16 b+b^{2}\right)(a-c)^{2}}{4(11-b)^{2}(1+b)}-F$ \\
\hline$d f$ & $\frac{3 c(9-b)-a(5-b)}{2 c(11-b)}$ & $\frac{(5-b)(a-c)}{11-b}$ & 0 & $\frac{(5-b)^{2}(a-c)^{2}}{2(11-b)^{2}}$ \\
\hline$d d$ & $\frac{2(2+b) c-a b^{2}}{\left(4+2 b-b^{2}\right) c}$ & $\frac{2(a-c)}{4+2 b-b^{2}}$ & 0 & $\frac{2\left(2-b^{2}\right)(a-c)^{2}}{\left(4+2 b-b^{2}\right)^{2}}$ \\
\hline
\end{tabular}

Table 2

Equilibrium under strategic delegation

\begin{tabular}{|l|l|l|l|}
\hline & $C S$ & $P S$ & $W$ \\
\hline$f f$ & $\frac{4(a-c)^{2}}{9(1+b)}$ & $\frac{4(a-c)^{2}}{9(1+b)}-2 F$ & $\frac{8(a-c)^{2}}{9(1+b)}-2 F$ \\
\hline$f d$ & $\frac{(25+7 b)(a-c)^{2}}{72(1+b)}$ & $\frac{(17-b)(a-c)^{2}}{36(1+b)}-F$ & $\frac{(59+5 b)(a-c)^{2}}{72(1+b)}-F$ \\
\hline$d d$ & $\frac{(1+b)(a-c)^{2}}{(2+b)^{2}}$ & $\frac{2(a-c)^{2}}{(2+b)^{2}}$ & $\frac{(3+b)(a-c)^{2}}{(2+b)^{2}}$ \\
\hline
\end{tabular}

Table 3

Consumer, producers and total surplus under strict profit maximization

\begin{tabular}{|l|l|l|l|}
\hline & $C S$ & $P S$ & $W$ \\
\hline$f f$ & $\frac{16(a-c)^{2}}{25(1+b)}$ & $\frac{8(a-c)^{2}}{25(1+b)}-2 F$ & $\frac{24(a-c)^{2}}{25(1+b)}-2 F$ \\
\hline$f d$ & $\frac{\left(433+111 b-33 b^{2}+b^{3}\right)(a-c)^{2}}{8(1+b)(11-b)^{2}}$ & $\frac{\left(41-8 b-b^{2}\right)(5-b)(a-c)^{2}}{4(1+b)(11-b)^{2}}-F$ & $\frac{3\left(281-17 b-9 b^{2}+b^{3}\right)(a-c)^{2}}{8(1+b)(11-b)^{2}}-F$ \\
\hline$d d$ & $\frac{4(1+b)(a-c)^{2}}{\left(4+2 b-b^{2}\right)^{2}}$ & $\frac{4\left(2-b^{2}\right)(a-c)^{2}}{\left(4+2 b-b^{2}\right)^{2}}$ & $\frac{4\left(3+b-b^{2}\right)(a-c)^{2}}{\left(4+2 b-b^{2}\right)^{2}}$ \\
\hline
\end{tabular}

Table 4

Consumer, producers and total surplus under strategic delegation 


\section{References}

Anderson S.P. And M. Engers, 1994, Strategic Investment and Timing of Entry. International Economic Review: 35, 833-853.

BÁrCena-Ruiz J.C. And M.P. Espinosa, 1997, Should multiproduct firms provide divisional or corporate incentives?. International Journal of Industrial Organization: 17, 751-764.

BÁrcena-Ruiz J.C. and N. Olaizola, 2004, Cost-Saving Production Technologies and Strategic Delegation. Mimeo.

Bester H. and E. Petrakis, 1993, The Incentives for Cost Reduction in a Differentiated Industry. International Journal of Industrial Organization: 11, $519-534$.

Elkins D.A., Huang N. And J.M. Alden, 2003, Agile Manufacturing Systems in the Automotive Industry. International Journal of Production Economics.

Fershtman C. and K. Judd, 1987, Equilibrium Incentives in Oligopoly. American Economic Review: 77, 927-940.

GöTz G., 2000, Strategic Timing of Adoption of New Technologies under Uncertainty: A Note. International Journal of Industrial Organization: 18, 369-379.

Hoppe H.C., 2000, Second-mover Advantages in the Strategic Adoption of New Technology under Uncertainty. International Journal of Industrial Organization: 18, 315-338.

Kim T. Röller L.H. And M.M. Tombak, 1992, Strategic Choice of Flexible Production Technologies and Welfare Implications: Addendum et Corrigendum. Journal of Industrial Economics: 2, 233-235. 
Röller L.H. AND M.M. Tombak, 1990, Strategic Choice of Flexible Production Technologies and Welfare Implications. Journal of Industrial Economics: 4, 417-431.

Saracho A.I., 2002, Patent Licensing under Strategic Delegation. Journal of Economics \&3 Management Strategy: 11, 225-251.

Sklivas S.D., 1987, The Strategic Choice of Management Incentives. Rand Journal of Economics: 18, 452-458.

Tseng M.C., 2003, Strategic Choice of Flexible Manufacturing Technologies. International Journal of Production Economics. Forthcoming.

Vives X., 1985, On the Efficiency of Cournot and Bertrand Competition with Product Differentiation. Journal of Economic Theory: 36, 166-175.

Vickers J., 1985, Delegation and the Theory of the Firm. Economic Journal: 43, 138-147. 
Firm 2

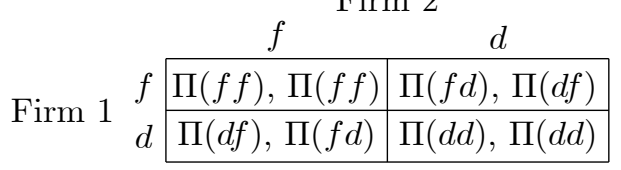

Figure 1. Summary of the game 


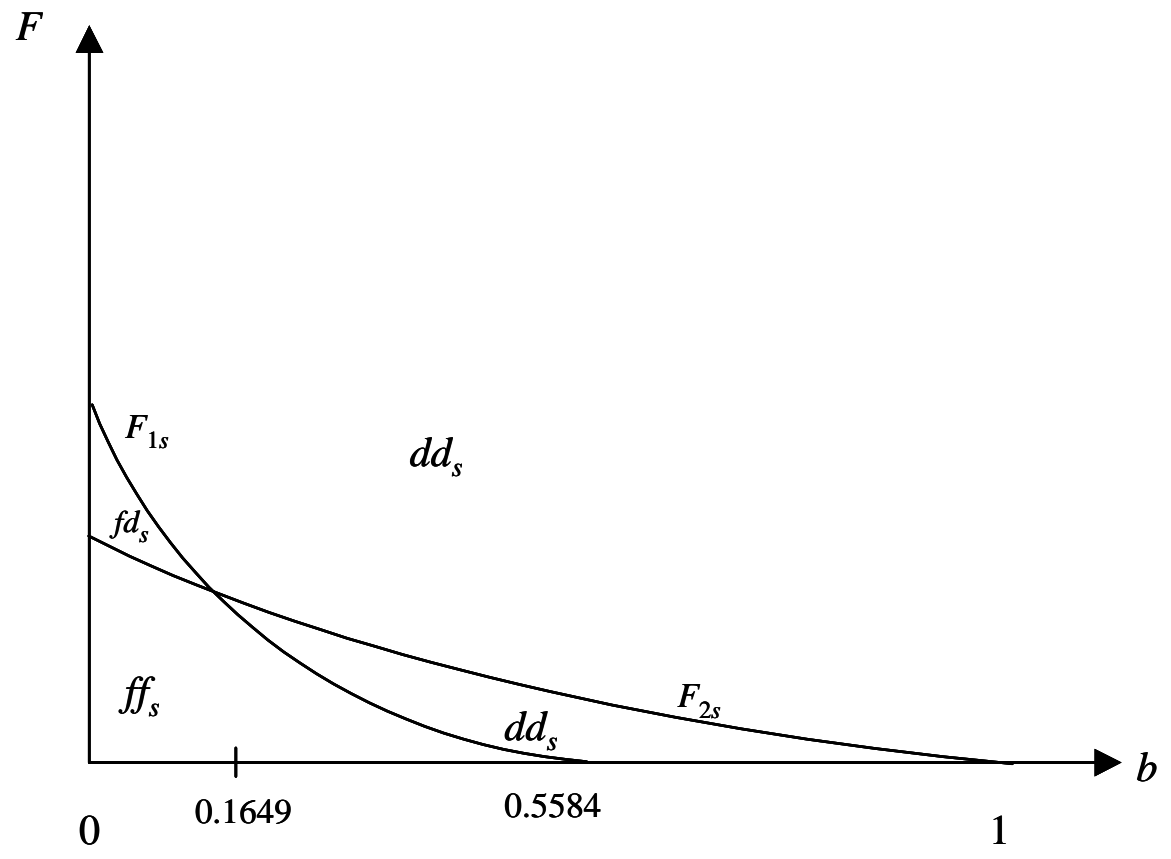

Figure 2. Technologies chosen under strategic delegation 


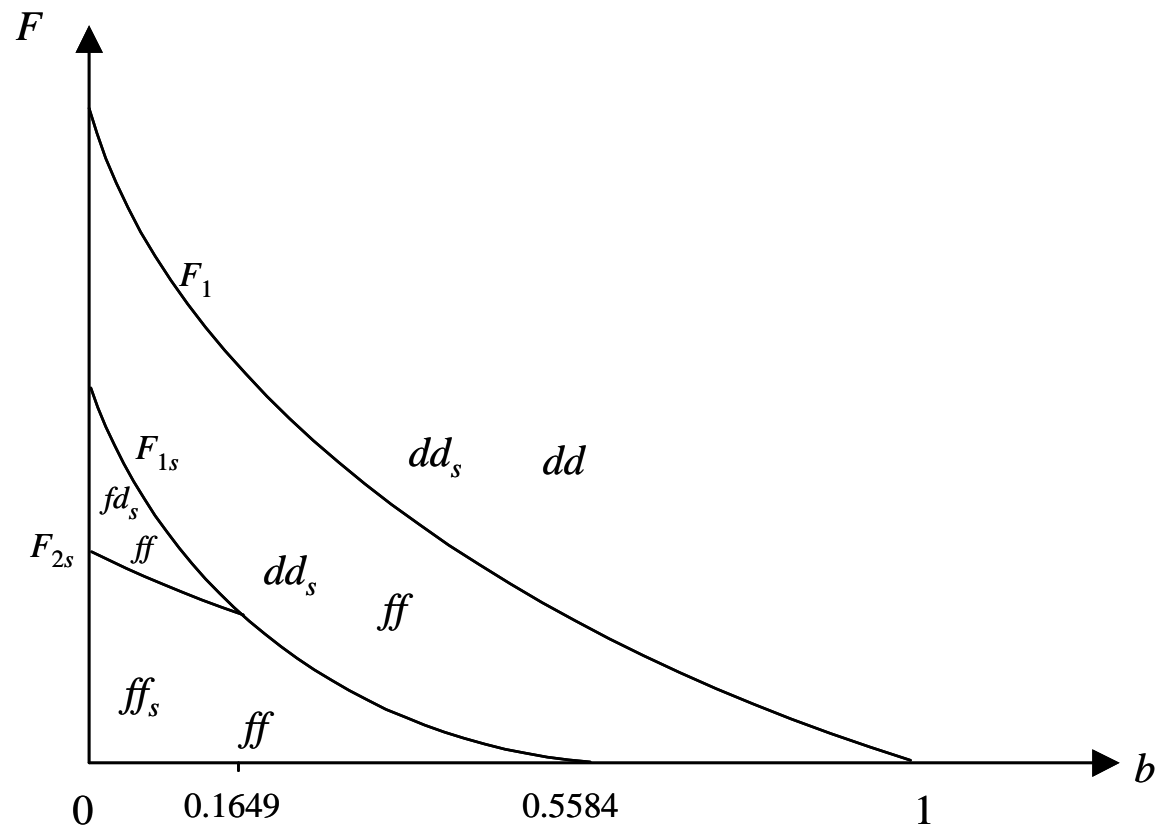

Figure 3. Comparison of the results obtained under strategic delegation and strict profit maximization 


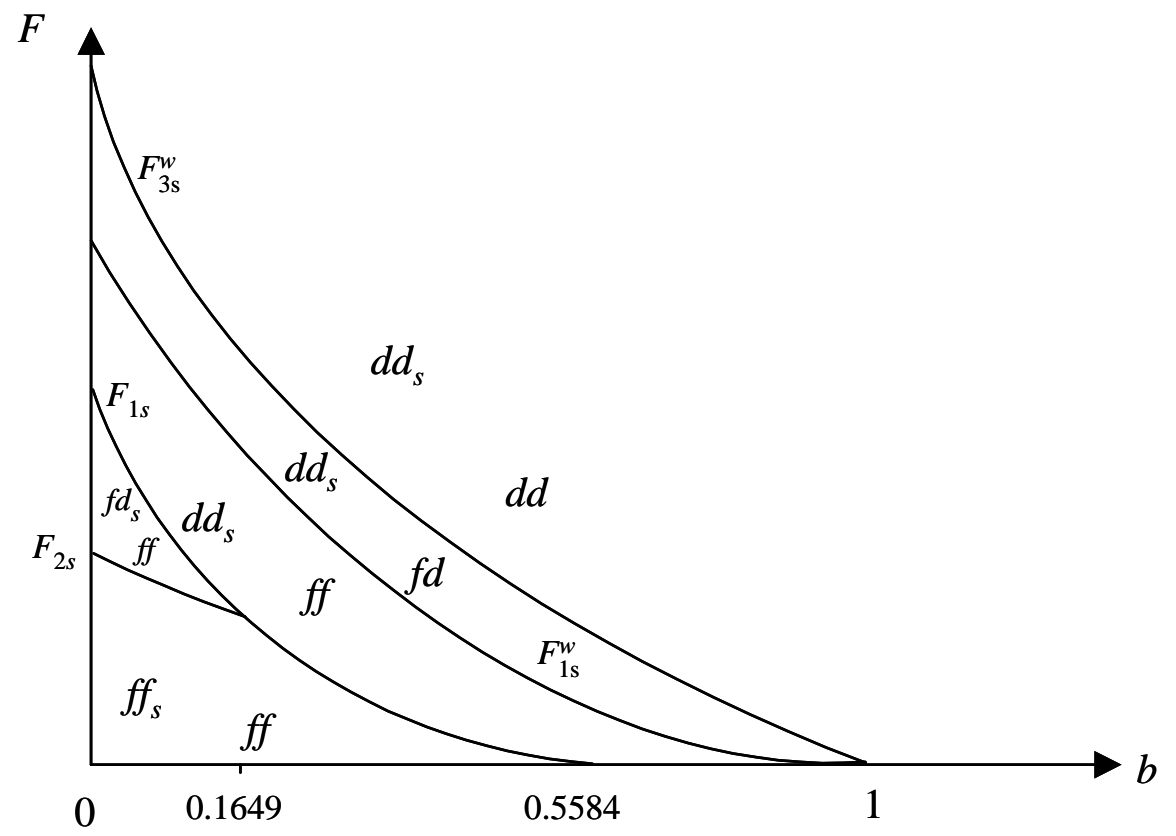

Figure 4. Comparison of the technologies chosen by owners with those that maximize total surplus 